\title{
EFEITO DE MÉTODOS DE COLETA DE FLUIDO RUMINAL EM BOVINOS SOBRE ALGUNS PARÂMETROS RUMINAIS E MICROBIOLÓGICOS'
}

\author{
MAURO DAL SECCO DE OLIVEIRA², ALEXANDRE AMSTALDEN MORAES SAMPAIO², \\ PAULO DE FIGUEIREDO VIEIRA ${ }^{3}$, JÚLIO CESAR MESTRINER DE FREITAS ${ }^{4}$ e RUBEN PABLO SHOCKEN-ITURRINO ${ }^{5}$
}

\begin{abstract}
RESUMO - Estudou-se o efeito de três métodos de coleta (manual, bomba a vácuo e sonda nasoesofageana) sobre os teores de ácidos graxos voláteis totais (AGVt), nitrogênio amoniacal e número de protozoários no fluido ruminal de bovino. Utilizou-se o delineamento inteiramente casualizado, com três tratamentos e cinco repetições. Os resultados revelaram que o método da sonda nasoesofageana proporcionou valores menores dos ácidos propiônico, butírico, AGVt e de nitrogênio amoniacal no fluido ruminal. O número total de protozoários não foi afetado pelos métodos de coleta de conteúdo ruminal. O método de coleta manual e por meio de bomba a vácuo mostraram-se eficientes para os parâmetros estudados.
\end{abstract}

Termos para indexação: ácido propiônico, bomba a vácuo, nitrogênio amoniacal, protozoários.

\section{EFFECT OF COLLECTION METHODS OF BOVINE RUMINAL FLUID ON RUMINAL AND MICROBIOLOGICAL PARAMETHERS}

\begin{abstract}
An experiment was conducted to determine the effects of three methods of collection on volatile fatty acids concentrations, amoniacal nitrogen levels and protozoa number in ruminal fluid of bovine. Three methods of collection were used: manual, vacuum-pump and with a nasal-esophagic tube. It was used a completely randomized design with three treatments and five replications. The data showed that the nasal-esophagic tube method resulted in lower values of propionic acid, butiric acid, volatile fatty acids and amoniacal nitrogen in ruminal fluid. The total number of protozoa do not affected by the methods of fluid collection. The manual and the vacuum-pump method showed an indicated methods for the determinations of the studied parameters.
\end{abstract}

Index terms: amoniacal nitrogen, propionic acid, protozoa, vacuum-pump.

\section{INTRODUÇÃO}

A avaliação de alimentos para uso animal pode ser feita por diversas técnicas, entre elas a digestão in vitro. Essa técnica permite, mediante a simulação das condições naturais da digestão, a obtenção de resultados representativos e confiáveis. No entanto, na etapa de coleta do conteúdo ruminal para

\footnotetext{
${ }^{1}$ Aceito para publicação em 11 de janeiro de 1999.

${ }^{2}$ Zoot., Dr., DZR, FCAVJ, UNESP, Rod. Carlos Tonanni, Km 5, CEP 14870-000 Jaboticabal, SP. Bolsista do CNPq. E-mail: mauro@fcav.unesp.br

${ }^{3}$ Eng. Agr., Dr., DZR, FCAVJ, UNESP.

${ }^{4}$ Zoot., Pós-graduando, FCAVJ, UNESP.

${ }^{5}$ Eng. Alimentos, Dr., Dep. Microbiologia, FCAVJ, UNESP.

E-mail: pablo@fcav.unesp.br
}

inocular as amostras de alimento, é fundamental que sejam preservadas as mesmas condições ruminais, o que exige uma retirada criteriosa e rápida. Dependendo do método de coleta, poderão ocorrer desvantagens que irão interferir nos resultados, principalmente dos parâmetros ruminais, tais como: $\mathrm{pH}$, temperatura, concentração de ácidos graxos voláteis e nitrogênio amoniacal (Raun \& Burroughs, 1962; Lane et al., 1966; Wolt et al., 1976; Ortolani, 1981; Kolb, 1984; Lavezzo et al., 1988) e microbiológicos, como o número de protozoários no fluido ruminal. Ainda podem ser citadas como fontes de variação o local de amostragem no rúmen e a diluição do conteúdo ruminal decorrente da ingestão de alimentos, de saliva e de água (Hungate, 1966; Lane et al., 1968; Mukherjee \& Sinha, 1990, citados por Freitas, 1995). 
Para a interpretação dos parâmetros de fermentação ruminal, é muito importante saber qual o método de coleta de conteúdo ruminal empregado, ou seja, se a amostra foi obtida via cânula ruminal (coleta manual), via sonda esofageana ou por meio de sonda nasoesofageana.

Apesar de o método de coleta manual permitir a retirada de conteúdo ruminal mais homogêneo (Wolt et al., 1976; Lavezzo et al., 1988), existe a desvantagem da manutenção do animal canulado. Por outro lado, o método de coleta por meio da sonda esofageana poderia contaminar o conteúdo com excesso de saliva, proporcionando, com isso, elevação no pH (Raun \& Burroughs, 1962; Ortolani, 1981) e diminuição nas concentrações de nitrogênio amoniacal (Wolt et al., 1976) e de ácidos graxos voláteis (Raun \& Burroughs, 1962). Segundo Lane et al. (1968), a análise do conteúdo ruminal proveniente de um só local proporcionou uma idéia irreal das condições prevalentes no rúmen.

Ainda que os métodos de coleta de conteúdo ruminal, via sonda, proporcionem alterações nos parâmetros ruminais, segundo Raun \& Burroughs (1962), quanto ao pH e ácidos graxos voláteis, as diferenças não foram relevantes. Todavia, a proporção molar do ácido acético foi maior em amostras coletadas pelo método manual em relação ao da sonda esofageana (Putnam et al., 1969).

O objetivo do presente ensaio foi determinar as possíveis variações de alguns parâmetros ruminais e microbiológicos em função dos métodos de coleta de conteúdo ruminal, em bovino alimentado com ração contendo silagem de milho e concentrado.

\section{MATERIAL E MÉTODOS}

Utilizou-se um bovino da raça holandesa pesando $550 \mathrm{~kg}$, com cânula ruminal permanente contendo duas aberturas. A retirada do fluido ruminal foi feita seqüencialmente por meio da coleta manual, com a bomba a vácuo e finalmente com a sonda nasoesofageana, com intervalos de aproximadamente 10 minutos. A cânula utilizada nos métodos manual e bomba a vácuo tinha duas aberturas, uma de $10 \mathrm{~cm}$ e outra de, aproximadamente, $2 \mathrm{~cm}$ de diâmetro, permitindo a passagem tanto do braço do coletador como da sonda ( $2 \mathrm{~cm}$ de diâmetro e $1,2 \mathrm{~m}$ de comprimento). No método da sonda nasoesofageana, utilizou-se uma sonda de $1,3 \mathrm{~cm}$ de diâmetro e, aproximadamente, de $2 \mathrm{~m}$ de comprimento, previamente lubrificada com furacin, até atingir o rúmen do animal. A retirada do fluido ruminal foi feita com bomba a vácuo, modelo 141 tipo 2 V.C. O animal recebeu ração constituída por $83,3 \%$ de volumoso e $16,7 \%$ de concentrado com base na matéria seca, diariamente, em duas refeições ( 8 e $15 \mathrm{~h}$ ) durante 20 dias. Utilizou-se a silagem de milho como volumoso, oferecida na quantidade diária de $30 \mathrm{~kg}$ em matéria natural, mais $5,0 \mathrm{~kg}$ de concentrado. $\mathrm{O}$ concentrado apresentou a seguinte composição percentual: milho desintegrado com palha e sabugo $=58$, farelo de trigo $=15$, farelo de algodão $=15$, farelo de soja $=10$ e sal mineralizado $=2$.

Foi utilizado o delineamento inteiramente casualizado, com três tratamentos e cinco repetições. Os dados foram comparados pelo teste de Tukey e para a contagem de microrganismos transformados em logaritmo. Foram estabelecidos os tratamentos que corresponderam aos métodos de coleta de conteúdo ruminal: manual, bomba a vácuo e sonda nasoesofageana.

Todas as coletas referentes às repetições foram feitas de manhã, após o 20 o dia de adaptação, com jejum de 12 horas. O conteúdo foi filtrado em saco de pano de algodão $(20 \times 22 \mathrm{~cm})$, mediante pressão manual, sendo retirado, primeiramente, por meio do método manual, em seguida, pelo método da bomba a vácuo, e, finalmente, pelo método da sonda nasoesofageana. O fluido foi mantido a $39-40^{\circ} \mathrm{C}$, em garrafas térmicas até as análises laboratoriais.

Os teores de ácidos graxos voláteis foram obtidos por meio de cromatógrafo a gás modelo SHIMADZU - GC 14B, coluna 100/120 CHR WAW 1,6 m x 3,2 mm. Os teores de nitrogênio amoniacal foram obtidos por meio da técnica modificada de Fenner (1965). O número total e a identificação de protozoários foi feita conforme Dehority (1984).

\section{RESULTADOS E DISCUSSÃO}

Na Tabela 1 são apresentados os dados referentes aos teores médios dos ácidos acético, propiônico, butírico e dos ácidos graxos voláteis totais (AGVt) e de nitrogênio amoniacal no fluido ruminal, retirado por meio dos diferentes métodos de coleta.

Notou-se diferença significativa entre os métodos com relação aos teores de ácido acético, cujas médias foram de 72,7, 73,2 e 75,4\% (P<0,01), respectivamente, nos métodos manual, bomba a vácuo e sonda nasoesofageana. A maior média foi obtida utilizando-se a sonda nasoesofageana, e a menor, por meio da retirada manual do fluido ruminal. 
No entanto, a superioridade da média de ácido acético obtida pelo método da sonda nasoesofageana foi de apenas 3,7\%. Considerando-se a média dos métodos $(73,7 \%)$, esta foi maior que a média de $69,37 \%$ de ácido acético obtida por Oliveira (1983), no fluido ruminal de bovinos alimentados com ração contendo feno. Normalmente, os teores de ácido acético são inferiores quando o conteúdo ruminal é obtido pelos métodos de coleta que possibilitam a contaminação por saliva, quando comparados com o método manual, porém, no presente ensaio houve comportamento inverso. Convém ressaltar que, segundo Putnam et al. (1969), dever-se-ia ter cautela na interpretação dos resultados, pois vários fatores poderiam interagir com o método de coleta. Lane et al. (1968) salientaram que devido à heterogeneidade do conteúdo ruminal, sua distribuição é desigual e estratificada e as amostras provenientes de um só local de amostragem poderiam causar variações nos resultados de AGVt. Esse aspecto é elucidado na Tabela 1, pois notou-se superioridade de 53,3\% na média de AGVt obtida pelo método manual em relação à média obtida pelo método da sonda nasoesofageana $(\mathrm{P}<0,01)$. Foram obtidas médias menores de ácido propiônico $(\mathrm{P}<0,01)$ e de ácido butírico $(\mathrm{P}<0,01)$ no método da sonda nasoesofageana em relação aos demais métodos.

Observou-se diferença nas médias de nitrogênio amoniacal nos diferentes métodos (Tabela 1). A menor média foi obtida no método da sonda nasoesofageana $(8,1 \%)$, que diferiu estatisticamente $(\mathrm{P}<0,01)$ das médias obtidas nos métodos manual
$(10,3 \%)$ e bomba a vácuo $(9,9 \%)$, às quais, por sua vez, não diferiram estatisticamente entre si. Segundo Griffiths \& Bath (1973) e Faria (1982), em dietas à base de silagem, os teores de nitrogênio amoniacal apresentam-se baixos. Comparando-se a média dos três métodos $(9,4 \%$ de nitrogênio amoniacal) com o valor de $8,6 \%$ obtido por Sampaio (1989) de bovinos alimentados com ração contendo feno de capim-coast-cross e levedura, verificou-se semelhança. Wolt et al. (1976), no entanto, observaram valores menores de nitrogênio amoniacal em amostras coletadas por via esofageana, ou seja, média de 14,3\% em relação à manual, cuja média foi de $19,7 \%$ em fluido ruminal de vacas alimentadas com feno de alfafa.

No presente ensaio, as médias foram semelhantes nos métodos manual e bomba a vácuo, demonstrando que a representatividade da amostra coletada pelo método da bomba a vácuo foi boa. Todavia, a coleta por via manual possibilitou valores maiores de nitrogênio amoniacal (Wolt et al., 1976). Possivelmente, a média inferior obtida no método da sonda nasoesofageana tenha ocorrido pelo fato de a coleta ter sido na região ventral do rúmen, uma vez que nesta região o teor de nitrogênio amoniacal é menor em relação ao teor obtido de fluido das regiões cranial e dorsal do rúmen (Wolt et al., 1976 e Abe \& Iriki, citados por Freitas, 1995).

Na Tabela 2 estão expressos o número total de protozoários, de entodinomorfos e de holotríquios $/ \mathrm{mL}$ de fluido ruminal obtido por meio dos diferentes métodos de coleta.

TABELA 1. Teores médios de ácido acético, ácido propiônico, ácido butírico, ácidos graxos voláteis totais (AGVt) e de nitrogênio amoniacal obtidos nos diferentes métodos de coleta de fluido ruminal ${ }^{1}$

\begin{tabular}{lccccc}
\hline $\begin{array}{l}\text { Métodos } \\
\text { de coleta }\end{array}$ & $\begin{array}{c}\text { Ácido } \\
\text { acético }(\%)\end{array}$ & $\begin{array}{c}\text { Ácido } \\
\text { propiônico }(\%)\end{array}$ & $\begin{array}{c}\text { Ácido } \\
\text { butírico }(\%)\end{array}$ & $\begin{array}{c}\text { AGVt } \\
(\mathrm{mL} / 100 \mathrm{~mL})\end{array}$ & $\begin{array}{c}\text { Nitrogênio } \\
\text { amoniacal }(\%)\end{array}$ \\
\hline Manual & $72,7 \mathrm{a}$ & $14,7 \mathrm{a}$ & $12,4 \mathrm{a}$ & $0,23 \mathrm{a}$ & $10,3 \mathrm{a}$ \\
Bomba a vácuo & $73,2 \mathrm{~b}$ & $14,6 \mathrm{a}$ & $12,1 \mathrm{a}$ & $0,22 \mathrm{~b}$ & $9,9 \mathrm{a}$ \\
Sonda nasoesofageana & $75,4 \mathrm{c}$ & $13,2 \mathrm{~b}$ & $11,3 \mathrm{~b}$ & $0,15 \mathrm{c}$ & $8,1 \mathrm{~b}$ \\
\hline Quadrado médio & $10,295^{* *}$ & $3,746^{* *}$ & $1,707^{* *}$ & $0,083^{* *}$ & $6,613^{* *}$ \\
Coeficiente de variação $(\%)$ & 0,28 & 1,20 & 1,89 & 1,73 & 8,19 \\
\hline
\end{tabular}

${ }^{1}$ Médias seguidas de letras iguais, na mesma coluna não diferem entre si, pelo teste de Tukey $(\mathrm{P}>0,05)$.

$* *(\mathrm{P}<0,01)$. 
TABELA 2. Número total de protozoários, de holotríquios e de entodinomorfos por mL no fluido ruminal obtido nos diferentes métodos de coleta de fluido ruminal ${ }^{1}$.

\begin{tabular}{|c|c|c|c|c|c|c|}
\hline \multirow[t]{2}{*}{ Método de coleta } & \multicolumn{2}{|c|}{$\begin{array}{l}\text { Número total de } \\
\text { protozoários }\end{array}$} & \multicolumn{2}{|c|}{$\begin{array}{l}\text { Protozoáros } \\
\text { holotríquios }\end{array}$} & \multicolumn{2}{|c|}{$\begin{array}{l}\text { Protozoários } \\
\text { entodinomorfos }\end{array}$} \\
\hline & Média & $\mathrm{Mt}^{2}$ & Média & Mt & Média & Mt \\
\hline Manual & 298.440 & $12,5 \mathrm{a}$ & 1.000 & $6,7 \mathrm{a}$ & 297.440 & $12,5 \mathrm{a}$ \\
\hline Bomba a vácuo & 242.760 & $12,3 \mathrm{a}$ & 240 & $2,8 b$ & 242.520 & $12,3 \mathrm{a}$ \\
\hline Sonda nasoesofageana & 177.000 & $11,9 \mathrm{a}$ & 440 & $5,8 \mathrm{ab}$ & 176.560 & $11,9 \mathrm{a}$ \\
\hline Quadrado médio & & $0,430^{\text {ns }}$ & & $20,897^{*}$ & & $0,428^{\mathrm{ns}}$ \\
\hline Coeficiente de variação (\%) & & 3,22 & & 35,49 & & 3,26 \\
\hline
\end{tabular}

${ }^{1}$ Médias seguidas de letras iguais, na mesma coluna não diferem entre si, pelo teste de Tukey $(\mathrm{P}>0,05)$.

2 Média transformada em DLOG $(X+2,00)$.

$*(\mathrm{P}<0,05)$.

${ }^{\text {ns }}$ Não-significativo.

Bryant \& Robinson (1962) relataram que apesar de a amônia ser o produto final resultante do processo fermentativo da proteína realizado pelos microrganismos ruminais, é também a principal fonte de nitrogênio usada para a síntese microbiana. No entanto, no presente trabalho, observou-se que o número total de protozoários não diferiu estatisticamente nos diferentes métodos de coleta. As médias variaram de 177.000 a 298.440 protozoários/mL de fluido ruminal. Segundo Hungate (1975) e Williams (1986) citado por Freitas (1995), a população de protozoários ruminais varia de 100.000 a $1.000 .000 / \mathrm{mL}$ de fluido ruminal. A média dos três tratamentos obtida no presente ensaio foi de 239.400 protozoários/mL de fluido ruminal, portanto, dentro da variação normal descrita para bovinos.

Os métodos de coleta não influíram estatisticamente no número de entodinomorfos, cujas médias foram de 297.440, 242.520 e 176.560 protozoários/mL de fluido ruminal, respectivamente, nos métodos manual, bomba a vácuo e sonda nasoesofageana (Tabela 2).

Houve diferença significativa no número de holotríquios $(\mathrm{P}<0,05)$, sendo a menor média (240 protozoários/mL de fluido ruminal) obtida no método da bomba a vácuo. Nesse sentido, a média do método manual (1.000 protozoários/mL) foi superior em $316,6 \%$ em relação à média do método com a retirada manual do fluido ruminal. Apesar de os holotríquios serem os protozoários ciliados ruminais em menor número e maior tamanho encontrados no fluido ruminal
(Abe et al., 1981, citados por Freitas, 1995), pode-se notar que o número de protozoários holotríquios foi muito baixo, independentemente do método de coleta. O número encontrado em bovinos é cerca de 100.000/mL de fluido ruminal (William \& Coleman, 1988, citados por Freitas, 1995), porém, ressalta-se que a oscilação verificada neste trabalho poderia ter ocorrido em virtude do tipo de dieta e tempo de amostragem pós-alimentação (Purser, 1961, citado por Freitas, 1995).

Os principais produtos da fermentação dos holotríquios são os ácidos lático, acético, butírico, $\mathrm{H}_{2}$ e $\mathrm{CO}_{2}$ (Williams \& Coleman, 1988, citados por Freitas, 1995), no entanto, apesar do menor número obtido no método da sonda nasoesofageana, houve maior produção de ácido acético, em relação ao método manual. Comparando-se o fluido obtido por meio do método manual e da bomba a vácuo, observou-se maior quantidade de protozoários holotríquios $(\mathrm{P}<0,05)$ no método manual, evidenciando a melhor representatividade do fluido ruminal do ponto de vista do número de protozoários.

\section{CONCLUSÕES}

1. O método de coleta de conteúdo ruminal por meio da sonda nasoesofageana é o menos indicado para a obtenção dos teores de ácidos graxos voláteis e de nitrogênio amoniacal.

2. O método de coleta não afeta o número total de protozoários, porém a coleta manual aumenta o número de protozoários holotríquios. 


\section{REFERÊNCIAS}

BRYANT, M.P.; ROBINSON, I.M. Some nutritional characteristics of predominant culturable ruminal bacteria. Journal Bacteriological, Baltimore, v.84, n.4, p.605-614, 1962.

DEHORITY, B.A. Evaluation of subsampling and fixation procedures used for counting rumen protozoa. Applied and Environmental Microbiology, v.48, p.182-185, 1984.

FARIA, V. P. de. Efeito de níveis de energia e de proteína sobre a fermentação no rúmen, a digestibilidade de princípios nutritivos e o desaparecimento de matéria seca de forragem na fermentação "in vitro" e em sacos suspensos no rúmen. Piracicaba: USP-ESALQ, 1982. 137p. Tese de Livre Docência.

FENNER, H. Methods for determining total volatile bases in rumen fluid by steam distillation. Journal of Dairy Science, Champaign, v.48, p.249, 1965.

FREITAS, J.C.M. Parâmetros ruminais associados às condições ambientais em ruminantes. Revisão bibliográfica. Jaboticabal: UNESP-FCAVJ, 1995. $13 \mathrm{p}$

GRIFFITHS, T.W.; BATH, I.H. Effects of energy and nitrogen supplementation of silage diets on rumen fermentation in fistulated heifers. Journal of Agricultural Science, Cambridge, v.80, n.1, p.89-95, 1973

KOLB, E. Fisiologia veterinária. 4.ed. Rio de Janeiro: Ed. Guanabara Koogan S/A, 1984. 612p.

LANE, G.T.; CUMMINGS, K.R.; NOLLER, C.H.; COLENBRANDER, V.F. A continuous flow device for obtaining ruminoreticular $\mathrm{pH}$ values and fluid samples. Journal of Animal Science, Champaign, v.25, n.3, p.1256-1261, 1966.

LANE, G.T.; NOLLER, C.H.; COLENBRANDER, V.F.; CUMMINGS, K.R.; HARRINGTON, R.B.
Apparatus for obtaining ruminoreticular samples and the effect of sampling location on $\mathrm{pH}$ and volatile fatty acids. Journal of Dairy Science, Champaign, v.51, n.1, p.114-116, 1968.

LAVEZZO, O.E.N.M.; FARIA, V.P.; MATTOS, W.R.S.; LAVEZZO, W. Influência de métodos de coleta de fluido ruminal sobre os parâmetros de fermentação em bovinos alimentados com diferentes fontes de proteína. Revista da Sociedade Brasileira de Zootecnia, Viçosa, v.17, n.3, p.281-291, 1988.

OLIVEIRA, M.D.S. Utilização da monensina na alimentação de bezerros com dietas de volumosos e concentrados. Jaboticabal: UNESP-FCAVJ. 1983. 53p. Tese de Mestrado.

ORTOLANI, E.L. Considerações técnicas sobre o uso da sonda esofágica na colheita do suco de rúmen de bovinos para mensuração do $\mathrm{pH}$. Arquivos da Escola de Veterinária da Universidade Federal de Minas Gerais, Belo Horizonte, v.33, n.2, p.269-275, 1981.

PUTNAM, P.A.; OLTJEN, R.R.; WILLIAMS JUNIOR, E. Type of fistulation and ruminal $\mathrm{pH}$ and VFA in steers. Journal of Animal Science, Albany, v.28, n.6, p.876, 1969.

RAUN, N.S.; BURROUGHS, W. Suction strainer technique in obtaining rumen fluid samples from intact lambs. Journal of Animal Science, Champaign, v.21, n.3, p.454-457, 1962.

SAMPAIO, A.A.M. Estudo da liberação de nitrogênio amoniacal "in vitro" e da digestão total e parcial de nutrientes em bovinos alimentados com rações contendo farelo de algodão, levedura e uréia. Jaboticabal: UNESP-FCAVJ. 1989. 112p. Tese de Doutorado.

WOLT, J.E.; CLARK, J.H.; BLAISDELL, F.S. Effect of sampling location, time, and method of concentration on ammonia nitrogen in rumen fluid. Journal of Dairy Science, Champaign, v.59, n.3, p.459-464, 1976. 